\title{
ВОЗДЕЙСТВИЕ ПРОФООРИЕНТИРОВАНИЯ ПО ТЕХНОЛОГИИ PROF.NAVIGATOR HA ПОВЫШЕНИЕ ВНЕУЧЕБНОЙ ЗАНЯТОСТИ ПОДРОСТКОВ
}

\section{IMPACT OF VOCATIONAL GUIDANCE USING PROF.NAVIGATOR TECHNOLOGY ON INCREASING THE EXTRACURRICULAR EMPLOYMENT OF ADOLESCENTS \\ O. Yatsenko \\ N. Cherneckaya E. Kedyarova}

Summary: The article presents a description and conclusions of a study on the impact of several career guidance technologies, including the author's PROF.Navigator technology, on the organized extracurricular activities of adolescents. The results of the study confirm the authors' hypothesis about a significant increase in extracurricular activities of adolescents, as a result of their career guidance. The study involved 120 teenagers from schools in the Irkutsk region, aged 14-18 years.

Keywords: career guidance of adolescents, extracurricular activities of adolescents, additional education of children, PROF.Navigator technology of career guidance.

\author{
Яченко Олег Валерьевич \\ аспирант, Иркутский государственный университет, \\ 2. Иркутск \\ olegyatsenko@inbox.ru \\ Чернецкая Надежда Игоревна \\ д.nсх.н., профессор, Иркутский государственный \\ университет, г. Иркутск \\ cherna@yandex.ru \\ Кедярова Елена Александровна \\ к.nсх.н., доцент, Иркутский государственный \\ университет, г. Иркутск \\ kedu_72@mail.ru
}

Аннотация: В статье представлены описание и выводы по исследованию 0 воздействии нескольких технологий профориентации, в том числе авторской технологии PROF.Navigator, на организованную внеучебную занятость подростков. Результаты исследования подтверждают гипотезу авторов 0 значимом повышении внеучебной занятости подростков, в результате их профориентирования. В исследовании участвовало 120 подростков из школ Иркутской области, в возрасте 14-18 лет.

Ключевые слова: профориентация подростков, внеучебная занятость подростков, внеурочная деятельность, дополнительное образование детей, технология профориентации PROF.Navigator.

тива. Профориентация, как процесс психолого-педагогического сопровождения профессионального самоопределения подростков, по мнению авторов, может служить достаточно эффективным средством в вопросах повышения организованной внеучебной занятости подростков.

Целью настоящего исследования была количественная и качественная оценка, сравнительный анализ возможностей трех различных технологий профориентации в решении задачи повышения внеучебной занятости подростков 14-18 лет. Для этого в исследовании были решены три основных задачи: выполнено теоретическое и эмпирическое обоснование выбора внеучебной занятости подростков как одного из количественных показателей успешности подростка, проведена количественная оценка сдвига во времени организованной внеучебной занятости, проведено сравнение эффективности воздействия различных технологий профориентации на время внеучебной занятости подростков.

Само понятие внеучебной занятости, которое имеет множество синонимов (внешкольная работа, внеурочная занятость и др.), уходит своими корнями в глубокое 
прошлое, когда еще в древнейших формах института образования, как культурного явления, отмечались различные формы активности обучающихся, не связанные с обучением [4]. Согласно принятому в педагогике определению [5], внеучебная занятость является составной частью учебно-воспитательного процесса, предпочтительными формами которой являются предметные кружки, научные общества, школы музыкального, художественного, технического творчества, спортивные секции. В своей работе мы исследовали организованную (структурированную) внеучебную занятость подростков, которая обеспечивается для подростка какой-либо внешней структурой (преподавателем, компанией, курсами и т.п.), имеет научного руководителя, наставника или тренера, а также имеет предполагаемые профессионально оцениваемые результаты.

В рассмотрении взаимосвязи внеучебной занятости и учебной успеваемости подростков мы опирались на выводы исследования [6], в котором убедительно была показана взаимосвязь между академической успеваемостью и занятостью школьников в организованных развивающих занятиях (кружках, секциях, факультативах, занятиях с репетитором, конференциях, лагерях). Поскольку ранее мы уже изучали влияние профориентации на учебную успеваемость подростков, мы решили дополнить свои исследования воздействия профориентации на образование подростка изучением ее воздействия на внеучебную занятость подростков.

Суть нашего исследования заключался в том, что в группах подростков был проведен формирующий эксперимент в виде индивидуальной профориентационной работы. Нами была оценена внеучебная занятость подростков (внешкольных занятий с репетиторами, в секциях, кружках, факультативах и пр.) в часах в неделю, в среднем в течение года до и в течение трех месяцев после формирующего эксперимента. В данном исследовании для нас было не так важно соответствие профиля этих развивающих занятий профилю выбранной подростками профессии в ходе профориентации, поскольку сильная корреляция учебной успеваемости и количества времени в кружках и секциях в исследовании [6] была выявлена и без учета профиля занятий. Для измерения учебной успеваемости до проведения эксперимента мы брали суммарный балл учащегося за итоговые прошлогодние оценки по математике, русскому языку и двум профильным предметам, определенным в ходе профориентации, а для измерения того же показателя после профориентации - сумму баллов по тем же предметам за учебную четверть после проведения профориентации.

У нашего исследования было три основные гипотезы: подтвердить выводы исследования [6], что между показателями учебной успеваемости и внеучебной занято- сти существует сильная корреляционная связь, что подтверждало бы предположение о том, что внеучебную занятость можно использовать как один из показателей учебной успешности подростка; внеучебная занятость под воздействием профориентации достоверно и значимо повышается, и данное повышение зависит от технологий профориентации, для чего необходимо оценить средний сдвиг во внеучебной занятости под воздействием разных технологий профориентации.

Наше исследование проходило на базе формирующего эксперимента с подростками 14-18 лет, обучающихся в общеобразовательных школах города Иркутска. База исследования составила 120 человек, отобранных на добровольной основе с согласия родителей и разделенных случайным образом на 4 группы по 30 человек в каждой - 3 экспериментальных и 1 контрольную. С участниками экспериментальных групп проводилась индивидуальная профориентационная работа по трем различным технологиям: профконсультировании на базе онлайн теста Центра гуманитарных технологий МГУ (методика «Профкарьера», авторы Серебряков А.Г., Алтухов В.В., Орлова Е.А., Кононов А.Н., Шмелев А.Г., далее по тексту - технология ЦГТ МГУ), технологии «Digital Human» Школы карьерного менеджмента (на базе методики «\#Профориентация» авторов Богдановская И.М., Кошелева А.Н.) и авторской технологии профориентации PROF.Navigator. Ранее мы уже подробно разбирали состав данных технологий профориентации [7]. Первые две технологии представляют собой широко применяемые в школах России электронные онлайн тесты, с последующим профессиональным консультированием на базе полученных после тестирования результатов. Третья технология разработана Яценко О.В. и более 8 лет используется в практической деятельности Центра профориентации PROF.Navigator. Она включает в себя определение готовности к выбору профессии по авторскому проблематизирующему опроснику; соционическую диагностику по методике Е.А. Удаловой; психодиагностику с выявлением акцентуаций характера по методу Леонгарда - Шмишека, тест Холланда на определение профессиональных предпочтений, тест самооценки, тест ценностных ориентаций личности; профессиональную диагностику с авторским биографическим опросником, изучением биографических материалов, собеседованием с родителями подростков, экспертизами профессиональных компетенций и достижений; профконсультирование с обучающим обзором мира профессий, подбором оптимальных профессий, профессиональной пробой или беседой с экспертом в выбранной профессии; выдачей отчета подростку в присутствии его родителей, с комментариями полученных в ходе профконсультирования результатов; мониторинг профессионального самоопределения с элементами тьюторского сопровождения. По времени формирующего воздействия тех- 
нология ЦГТ МГУ заняла в среднем 3 часа работы с подростком, технология Digital Human - 4 часа, технология PROF.Navigator - 12 часов. В контрольной группе работа по профориентации с подростками не проводилась.

Для оценки корреляции между показателями учебной успеваемости и внеучебной занятости мы использовали коэффициент ранговой корреляции Спирмена, т.к. объемы выборок по группам не превышают 40 человек, и у нас отсутствует нормальное распределение признаков. Для оценки сдвигов во внеучебной занятости мы использовали критерий G-критерий знаков и угловое преобразование Фишера $\varphi^{*}$, по тем же причинам.

В результате исследования, мы получили следующие корреляционные связи между учебной успеваемостью и внеучебной занятостью, окторые представлены в таблице 1.

Действительно, показатель внеучебной занятости подростков во всех группах сильно коррелировал с успеваемостью. Особо отметим группу PROF.Navigator, в которой корреляционная связь усилилась после формирующего эксперимента сильнее всего. Это связано с тем, что профконсультанты по технологии PROF.Navigator делают в консультациях с подростками и их родителями особый акцент на роль дополнительного образования в карьерном успехе и фактически прямо указывают на конкретные кружки, секции, курсы и тренинги, которые рекомендуют подростку пройти в ближайшее время. Так, например, в группе PROF.Navigator имелось
5 подростков, которым было рекомендовано сразу после прохождения профориентации принять участие в 7-дневном развивающем мероприятии - выездной сессии Международной школы молодежной дипломатии при университете МГИМО, с чем подростки с радостью согласились и осуществили, резко увеличив свою внеучебную занятость.

По результатам изучения сдвигов в показателях внеучебной занятости испытуемых, мы получили следующие значения показателей, представленные в таблице 2 .

Из расчетов следует, что в длительности внеучебной занятости подростков под воздействием профориентации произошли достоверные и значимые сдвиги. Профориентация сыграла важную роль в росте времени организованной внеучебной занятости, что объясняется акцентом профконсультирования на обсуждении с подростками их индивидуальной образовательной траектории и рекомендациях различных развивающих занятий. Особенно выделилась в эксперименте группа PROF.Navigator, увеличившая в среднем на 55\% время развивающих занятий, за счет более длительной формирующей работы, встраивании внеучебной занятости в индивидуальную образовательную траекторию, активной работе с родителями подростков по скорейшему запуску дополнительных развивающих занятий, либо корректировке существующих.

По результатам проведенного исследования мы можем сделать вывод о том, что профориентация имела до-

Таблица 1.

Корреляционные связи между занятостью испытуемых и их успеваемостью по сумме баллов 4 предметов

\begin{tabular}{|c|c|c|c|c|}
\hline Группы испытуемых & Контрольная группа & Группа PROF.Navigator & Группа Digital Human & Группа ЦГТ мГУ \\
\hline $\begin{array}{l}r_{s} \text { между средним временем развивающих } \\
\text { занятий и суммой баллов по 4 предметам }\end{array}$ & $0,47 / 0,48$ & $0,45 / 0,66$ & $0,56 / 0,49$ & $0,58 / 0,57$ \\
\hline
\end{tabular}

Таблица 2.

Сдвиг показателей внеучебной занятости по группам испытуемых

\begin{tabular}{|l|c|c|c|c|}
\multirow{2}{*}{ Экспериментальные группы } & \multicolumn{2}{|c|}{ Среднее время сдвига внеучебной занятости } & Значение критерия G знаков & $\begin{array}{c}\text { 3начение углового преоб- } \\
\text { разования Фишера } \varphi^{*}\end{array}$ \\
\cline { 2 - 5 } & часов в неделю & $\%$ & 0 & 5,19 \\
\hline PROF.Navigator & 4,4 & 55,1 & 1 & 1,08 \\
\hline Digital Human & 0,8 & 9,5 & 1 & 0,55 \\
\hline ЦГТ МГу & 0,77 & 12,1 & 4 & - \\
\hline
\end{tabular}

*При расчетах G-знаков нет постоянных Gкр., поскольку n колеблется в каждом отдельном случае в зависимости от количества «нулевых реакций» в сопоставляемых массивах данных.

**3начения $\mathrm{G}$, говорящие о достоверном сдвиге хотя бы при $p<0,05$, обозначены жирным шрифтом.

***При расчетах $\varphi^{*}$ критические для него являются постоянными: $\varphi^{*}=2,28$ при $p<0,01$. Эмпирические значения $\varphi^{*}$, говорящие о достоверных различиях между сравниваемыми группами, здесь и далее отмечены жирным шрифтом. 
стоверное и значимое воздействие на повышение внеучебной занятости подростков. Среди трех технологий профориентации, задействованных в формирующем эксперименте, наибольшим воздействием на внеучебную занятость подростков имела авторская технология PROF. Navigator, которая позволила существенно увеличить ее в среднем на 55\% от исходного времени внешкольных занятий в течение 3 месяцев после формирующего воздействия. Таким образом, мы считаем целесообразным использование времени внеучебных занятий как одного из надежных показателей учебной успеваемости, а профориентации по технологии PROF.Navigator в качестве эффективного средства повышения внеучебной занятости подростков.

\section{ЛИТЕРАТУРА}

1. Александров Д.А., Тенишева К.А., Савельева С.С. Связь внеклассных занятий с учебными успехами и самооценкой подростков // Вопросы образования. 2017. №4. URL: https://cyberleninka.ru/article/n/svyaz-vneklassnyh-zanyatiy-s-uchebnymi-uspehami-i-samootsenkoy-podrostkov (дата обращения: 07.10.2021).

2. Игнатова 0.А. 0 проблемах занятости учащихся во внеурочное время. // Сетевое издание «Солнечный свет». - URL: https://solncesvet.ru/opublikovannyiematerialyi/o-problemah-zanyatosti-uchashchihsya-vo-vne (дата обращения 01.10.2021)

3. Разварина И.Н., Гордиевская А.Н. Образование как фактор профессионального самоопределения подростков // Научный результат. Педагогика и психология образования. 2020. T.6. №4. C. 3-15. D0I: 10.18413/2313-8971-2020-6-4-0-1

4. Андреева Е.В. Генезис и сущность внеучебной деятельности в системе профессионального образования // Сибирский педагогический журнал. 2009. №11. URL: https://cyberleninka.ru/article/n/genezis-i-suschnost-vneuchebnoy-deyatelnosti-v-sisteme-professionalnogo-obrazovaniya (дата обращения: 05.10.2021).

5. Российская педагогическая энциклопедия. В 2-х т. Т. 1 / Под ред. В.В. Давыдова. -М.: Большая российская энциклопедия, 1993. - 680 с.

6. Поливанова К.Н., Лебедев М.В., Сивак Е.В. Внешкольная занятость детей // Директор школы. - М., Издательство 000 «Издательская фирма «Сентябрь»». - 2016. №3(206). С. 76-81.

7. Яценко 0.В. К вопросу о создании новых технологий профориентации современных подростков // Проблемы теории и практики современной психологии: Материалы XIX Всероссийской научно-практической конференции с международным участием. Иркутск, 23-24 апреля 2020 г. Иркутск: Издательство ИГУ, 2020. С. 191-194

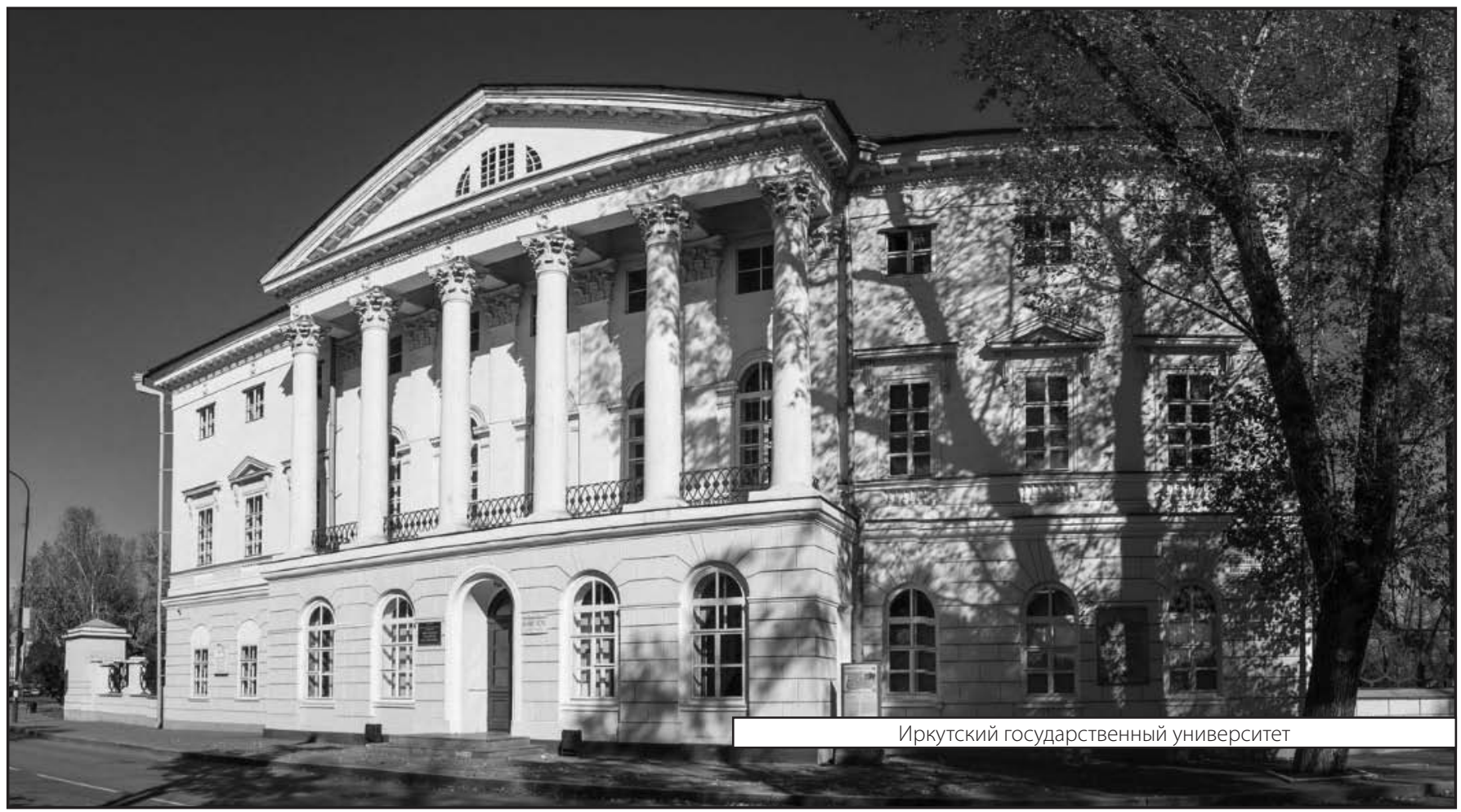

